\title{
CHARACTERISTICS OF PATIENTS WITH ORGANOPHOSPHORUS POISONING AND ITS MANAGEMENT: PHARMACOEPIDEMIOLOGICAL EVALUATION
}

\author{
MADHURI KULKARNI ${ }^{1 *}$, ANANT PATIL ${ }^{2}$ \\ ${ }^{1}$ Department of Pharmacology, Government Medical College, Aurangabad, Maharashtra, India. ${ }^{2}$ Department of Pharmacology, Dr. DY Patil \\ Medical College, Nerul, Navi Mumbai, Maharashtra, India. Email: anantdpatil@gmail.com \\ Received: 04 September 2018, Revised and Accepted: 19 September 2018
}

\section{ABSTRACT}

Objective: The objective of this study was to analyze demographics, management pattern, and clinical outcomes in patients with organophosphorus poisoning.

Methods: In this subgroup analysis of retrospective data of patients admitted in intensive care unit (ICU) with a diagnosis of acute organophosphorus poisoning, demographic details, pattern of use of medicines, dose of atropine and pralidoxime (PRAM), duration of ICU stay, and clinical outcomes were analyzed.

Results: A total of 92 patients with organophosphorus poisoning (mean age 34.7 years; male 69 [75\%]) were included. The age of male patients was more than female patients ( 36.2 vs. 30.0 years; $p=0.047$ ). Atropine and PRAM were given to all patients. Ondansetron was used in all patients, whereas ranitidine was used in 91 (98.9\%) patients. The mean total dose of atropine in male and female population was $99.5 \mathrm{mg}$ and $89.0 \mathrm{mg}$, respectively $(\mathrm{p}=0.298)$. The mean total dose of PRAM in male and female population was $12.2 \mathrm{mg}$ and $12.0 \mathrm{mg}$, respectively ( $\mathrm{p}=0.772$ ). There was no difference in the mean (standard deviation) duration of stay in ICU between male patients and female patients (7.6 [4.5] vs. 6.4 [3.9] days; $p=0.249$ ). A total of $61(66.3 \%)$ patients were transferred to the ward, whereas $30(32.6 \%)$ died.

Conclusion: Atropine and PRAM are the primary drugs for the treatment of organophosphorus poisoning. Ondansetron and ranitidine are useful drugs for the treatment of vomiting and gastric irritation, respectively, in these patients.

Keywords: Atropine, Intensive care unit, Organophosphorus poisoning.

(C) 2019 The Authors. Published by Innovare Academic Sciences Pvt Ltd. This is an open access article under the CC BY license (http://creativecommons. org/licenses/by/4. 0/) DOI: http://dx.doi.org/10.22159/ajpcr.2019.v12i2.28835

\section{INTRODUCTION}

Acute poisoning with organophosphorus compounds is one of the major concerns, especially in developing countries [1] including India [2-4] because of its high mortality rate [2,3]. A study from India has reported a mortality rate of $22.6 \%$ among hospitalized patients with pesticide poisoning [5].

Organophosphorus poisoning is nota single entity [6]. Organophosphorus compounds are the group of compounds with strong anticholinesterase activity. These are often used as insecticides and pesticides [7].

The symptoms of organophosphorus poisoning include those because of muscarinic and nicotinic receptor stimulation [7]. Patients with organophosphorus poisoning often require admission in the intensive care unit (ICU) [8]. The goals of the treatment of acute organophosphorus poisoning include limiting absorption of the toxin, increasing excretion of poison, and neutralizing the effects of organophosphorus compound by giving antagonist [9].

Overall treatment strategy of acute organophosphorus poisoning includes resuscitation, oxygen, intravenous fluids, antimuscarinic agent, acetylcholinesterase reactivator, and gastric lavage [10]. Atropine, a muscarinic antagonistic, is a mainstay of treatment in acute organophosphorus poisoning [9]. Pralidoxime (PRAM) is another important compound in the treatment of acute organophosphorus poisoning [3].

Although poisoning with organophosphorus compounds is common, there are no large, systematic epidemiological studies from India [7]. Similarly, there are limited pharmacoepidemiological data related to organophosphorus compound poisoning from Maharashtra.
Objective

The objective of this study was to analyze demographics, management pattern, and clinical outcomes of patients with organophosphorus poisoning admitted in the medical ICU.

\section{METHODS}

Recently, a retrospective study among patients admitted in medical ICU with a diagnosis of acute poisoning was published [11]. In this article, we analyzed the subgroup of patients with organophosphorus poisoning admitted in medicine ICU from January 2017 to July 2017. Demographic details (age and gender) were collected. Different medicines used for the treatment of organophosphorus poisoning, dose of atropine, and PRAM were calculated. The difference in the dosage of these two medicines was analyzed. Duration of ICU stay was calculated. Clinical outcomes of male and female patients were compared. Approval from the institutional ethics committee was taken for the main study. As this is a subgroup analysis of larger data set, a separate approval from ethics committee was not obtained.

\section{Statistical analysis}

Continuous data are presented as mean and standard deviation (SD), whereas categorical data are presented as number and percentages. Unpaired t-test was used to compare the difference in the means between two groups. Categorical data were compared using Chi-square test. $\mathrm{p}<0.05$ was considered as statistically significant.

\section{RESULTS}

A total of 92 patients with organophosphorus poisoning were included in this study. The mean age of patients in the study was 34.7 years. The study population was predominated by male population $(75 \%$ vs. 
$25 \%)$. There was a significant difference in the age of male and female patients ( 36.2 vs. 30.0 years; $p=0.047$; Table 1 )

Table 2 shows a list of medicines used in the treatment of patients with organophosphorus poisoning. The drugs were classified into four types based on their usage; those used as primary treatment, drugs for gastrointestinal disturbances, antimicrobial agents, and hypnotic/ sedatives. Primary treatment in the form of atropine and PRAM was given to all patients with organophosphorus poisoning. Drugs used for the treatment of gastrointestinal disturbances included ondansetron and ranitidine. Ondansetron was used in all patients, whereas ranitidine was used in 91 (98.9\%) patients. The antimicrobial agents used in patients with organophosphorus poisoning included ceftriaxone (70.7\%), metronidazole $(29.3 \%)$, cefotaxime $(28.3 \%)$, amoxicillinclavulanic acid (23.9\%), amikacin (4.4\%), meropenem (3.3\%), and piperacillin plus tazobactam combination (3.3\%). Hypnotic/sedatives used were midazolam (20.7\%) and lorazepam (7.6\%).

The mean total dose of atropine used in overall patient population, male population, and female population was $96.8,99.5$, and $89.0 \mathrm{mg}$, respectively (Table 3). There was no difference in the dose of atropine between male and female patients with organophosphorus poisoning $(p=0.298)$. The mean total dose of PRAM in overall patient population, male population, and female population was $12.1,12.2$, and $12.0 \mathrm{mg}$, respectively (Table 3 ). There was no difference in the dose of PRAM between male and female patients with organophosphorus poisoning $(\mathrm{p}=0.772)$.

The mean (SD) duration of stay in ICU for overall patient population, male patients, and female patients was 7.3 (4.7), 7.6 (4.5), and 6.4 (3.9), respectively (Fig. 1). There was no difference in the duration of hospital stay between male and female patients $(p=0.249)$.

A total of $61(66.3 \%)$ patients were transferred to the ward, whereas $30(32.6 \%)$ died. One patient was discharged against medical advice (Table 4). There was no significant difference in male and female

Table 1: Baseline characteristics of study population $(n=92)$

\begin{tabular}{ll}
\hline Characteristics & Result \\
\hline Mean (SD) age & $34.7(13.1)$ years \\
Mean (SD) age of male patients & $36.2(13.1)$ years \\
Mean (SD) age of female patients & $30.0(12.3)$ years \\
Male, n (\%) & $69(75)$ \\
Female, n (\%) & $23(25)$ \\
\hline
\end{tabular}

SD: Standard deviation

Table 2: Medicines used for the treatment of patients with organophosphorus poisoning $(n=92)$

\begin{tabular}{ll}
\hline Drug & n (\%) \\
\hline Primary medicines & $92(100)$ \\
Atropine & $92(100)$ \\
PRAM & \\
Drugs for gastrointestinal & \\
disturbance & $92(100)$ \\
Ondansetron & $91(98.9)$ \\
Ranitidine & \\
Antimicrobial agents & $65(70.7)$ \\
Ceftriaxone & $27(29.3)$ \\
Metronidazole & $26(28.3)$ \\
Cefotaxime & $22(23.9)$ \\
Amoxycillin-clavulanic acid & $4(4.4)$ \\
Amikacin & $3(3.3)$ \\
Meropenem & $3(3.3)$ \\
Piperacillin and tazobactam & \\
Hypnotic/sedative & $19(20.7)$ \\
Midazolam & $7(7.6)$ \\
Lorazepam &
\end{tabular}

patients in terms of a number of patients transferred to the ward and those died $(\mathrm{p}=0.765)$.

\section{DISCUSSION}

Acute poisoning is an important cause of hospitalization [12,13]. Selfpoisoning with pesticides is a concern, especially in rural areas, because of easy access to toxic pesticides [14] and high rate mortality [15].

Unlike a study from Nepal [2], in our study, male population was more affected because of organophosphorus poisoning. Our results are similar to other studies from India [16-18], showing more occurrence of poisoning in male population compared to female population. As reported in other studies $[2,16]$, people from working population were more commonly affected in our study too. The results of our study suggest that working male population is more affected by organophosphorus poisoning. We did not record the occupation and marital status of people affected, but it may have some association with organophosphorus poisoning [2]

Mortality in acute organophosphorus poisoning is usually because of respiratory failure and cardiovascular collapse due to cholinergic effects of the poison [19]. Atropine is an essential medicine for the treatment of organophosphorus poisoning. Serious cases cannot be managed without atropine [14]. Atropine remains the choice of drug for the management of cholinergic crisis in acute organophosphorus poisoning [3]. However, there are variations in the recommendations for atropinization [19].

Table 3: Total dose of atropine and PRAM used in patients with organophosphorus poisoning

\begin{tabular}{lll}
\hline Patient population & $\begin{array}{l}\text { Mean total } \\
\text { dose of } \\
\text { atropine }(\mathbf{m g})\end{array}$ & $\begin{array}{l}\text { Mean total } \\
\text { dose of } \\
\text { PRAM (mg) }\end{array}$ \\
\hline Overall patient population $(\mathrm{n}=92)$ & $96.8(41.5)$ & $12.1(3.3)$ \\
Male patients $(\mathrm{n}=69)$ & $99.5(41.5)$ & $12.2(3.4)$ \\
Female patients $(\mathrm{n}=23)$ & $89.0(41.2)$ & $12.0(3.0)$ \\
\hline
\end{tabular}

PRAM: Pralidoxime

Table 4: Outcomes of patients with organophosphorus poisoning

\begin{tabular}{|c|c|c|c|}
\hline Outcome & $\begin{array}{l}\text { Overall patient } \\
\text { population } n=92(\%)\end{array}$ & $\begin{array}{l}\text { Male } \\
n=69(\%)\end{array}$ & $\begin{array}{l}\text { Female } \\
n=23(\%)\end{array}$ \\
\hline $\begin{array}{l}\text { Transferred to the } \\
\text { ward }\end{array}$ & $61(66.3)$ & $45(65.2)$ & $16(69.6)$ \\
\hline Mortality & $30(32.6)$ & $23(33.3)$ & $7(30.4)$ \\
\hline $\begin{array}{l}\text { Discharged against } \\
\text { medical advice }\end{array}$ & $1(1.1)$ & $1(1.5)$ & 0 \\
\hline
\end{tabular}

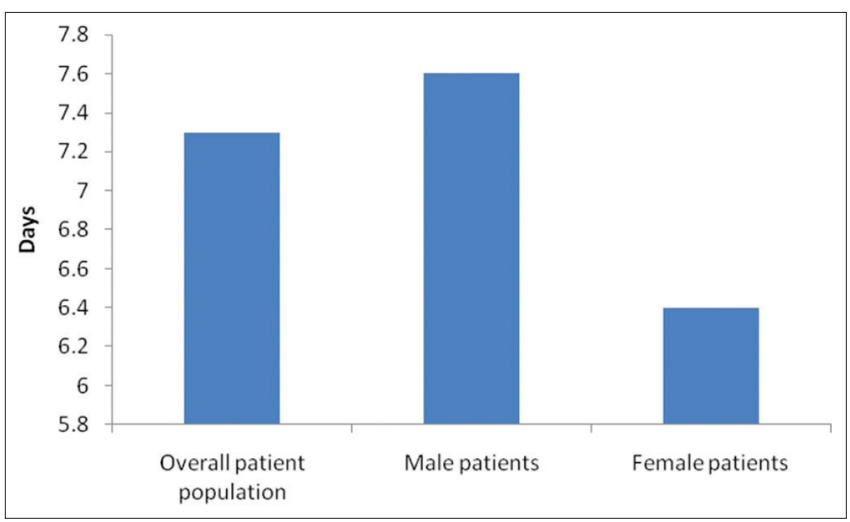

Fig. 1: Mean duration in intensive care unit stay of patients with organophosphorus poisoning 
Glycopyrrolate is another anticholinergic drug that can be used for the treatment of organophosphorus poisoning [20]. In our study, all patients received atropine. In other studies too, all patients received atropine [18]. The mean total dose of atropine used in our study was $96.8 \mathrm{mg}$

Atropine is ineffective at the nicotine-sensitive synapses. Reactivation of inhibited cholinesterase may be beneficial at both muscarinic and nicotinic receptors [21]. PRAM helps in restoring phosphorylated cholinesterase enzyme which is significantly inhibited in patients with organophosphorus poisoning. PRAM is useful for improving symptoms of muscle weakness and fasciculations [3]. In our study, all patients were treated with PRAM. High dose of PRAM has been shown to be associated with better survival as compared with lower dose [3]. In our study, mean total dose of PRAM used was $12.1 \mathrm{~g}$. The requirement of PRAM in our study was similar to another study [20]. We did not find a significant difference in the dosing requirement of atropine and PRAM in male and female patients.

More than 5 days of stay in the hospital is common for patients with organophosphorus compound poisoning [16]. In our study, the mean duration of stay in ICU was 7.3 days. Our observation regarding hospital stay is similar to that reported by Kumar et al. [18].

Mortality rate due to organophosphorus poisoning in our study was similar to that of reported in another study from Gujarat [16].

Our study provides significant insights in terms of gender-wise comparison of characteristics in patients with organophosphorus poisoning. The results of our study underline the need and importance of education of the working population regarding harmful effects of organophosphorus compounds. Education and awareness may help to reduce the morbidity and mortality associated with acute organophosphorus poisoning.

Limitations of our study include retrospective study design, singlecenter study, and small sample size. Considering these limitations, the results of our study should be carefully interpreted and extrapolated.

\section{CONCLUSION}

Atropine and PRAM are the primary drugs used in the treatment of organophosphorus poisoning. There is no difference in the mean total dosage of these drugs and duration of stay in ICU between male and female population. Ondansetron and ranitidine are useful drugs for the treatment of vomiting and gastric irritation, respectively, in these patients.

\section{ACKNOWLEDGMENT}

Authors of this study wish to thank Dr. Siddharth Athawale for his contribution in data collection.

\section{AUTHORS' CONTRIBUTIONS}

Dr. Madhuri Kulkarni conceptualized the study. Dr. Anant Patil conducted statistical analysis. Both the authors contributed for the preparation of manuscript.

\section{CONFLICTS OF INTEREST}

The authors have no conflicts of interest.

\section{REFERENCES}

1. Eddleston M, Karalliedde L, Buckley N, Fernando R, Hutchinson G, Isbister $\mathrm{G}$, et al. Pesticide poisoning in the developing world-a minimum pesticides list. Lancet 2002;360:1163-7.

2. Mishra A, Shukla SK, Yadav MK, Gupta AK. Epidemiological study of medicolegal organophosphorus poisoning in central region of Nepal. J Forensic Res 2012;3:167.

3. Shivakumar S, Raghavan K, Ishaq RM, Geetha S. Organophosphorus poisoning: A study on the effectiveness of therapy with oximes. J Assoc Physicians India 2006;54:250-1.

4. Patil G, Murthy N, Nikhil M. Contributing factors for morbidity and mortality in patients with organophosphate poisoning on mechanical ventilation: A retrospective study in a teaching hospital. J Clin Diagn Res 2016;10:UC18-20.

5. Ch SR, Venkateswarlu V, Surender T, Eddleston M, Buckley NA. Pesticide poisoning in South India: Opportunities for prevention and improved medical management. Trop Med Int Health 2005;10:581-8.

6. Eddleston M, Eyer P, Worek F, Mohamed F, Senarathna L, von Meyer L, et al. Differences between organophosphorus insecticides in human self-poisoning: A prospective cohort study. Lancet 2005;366:1452-9.

7. Singh G, Khurana D. Neurology of acute organophosphate poisoning. Neurol India 2009;57:119-25.

8. Bardin PG, Van Eeden SF. Organophosphate poisoning: Grading the severity and comparing treatment between atropine and glycopyrrolate. Crit Care Med 1990;18:956-60.

9. PalaniappenV.CurrentConceptsintheManagementofOrganophosphorus Compound Poisoning API. Ch. 95; Available from: http://www. apiindia.org/medicine_update_2013/chap95.pdf. [Last accessed on 2018 Jul 29].

10. Eddleston M, Buckley NA, Eyer P, Dawson AH. Management of acute organophosphorus pesticide poisoning. Lancet 2008;371:597-607.

11. Athawale S, Kulkarni MD, Doifode SM. Drug utilization pattern of acute poisoning admissions in medicine intensive care unit. Indian $\mathrm{J}$ Pharm Pharmacol 2018;5:93-6.

12. Khan PA, Chary MD, Kumar MM, Nousheen BB. A study on treatment pattern and outcomes of poisoning cases in a tertiary care and government district hospital. Int J Pharm Pharm Sci 2017;9:193-7.

13. Reddy S, Revathi D, Prasanna VL, Ramesh AC. Sociodemographic profile of patients with acute poisoning in the emergency wards of a tertiary care hospital. Int J Pharm Pharm Sci 2018;10:50-6.

14. Eddleston M, Phillips MR. Self-poisoning with pesticides. BMJ 2004;328:42-4.

15. Eddleston M. Patterns and problems of deliberate self-poisoning in the developing world. QJM 2000;93:715-31.

16. Shah NM, Mundhra SH. Clinical profile of organophosphate poisoning at a tertiary-care center. Int J Med Sci Public Health 2016;5:1621-5.

17. Joshi SC, Prakash C, Joshi A, Joshi G. Profile of organophosphorus poisoning at tertiary care hospital in Uttarakhand. J Indian Acad Forensic Med 2013;35:346-8.

18. Kumar MR, Kumar GP, Babu PR, Kumar SS, Subrahmanyam BV, Veeraprasad M, et al. A retrospective analysis of acute organophosphorus poisoning cases admitted to the tertiary care teaching hospital in South India. Ann Afr Med 2014;13:71-5.

19. Eddleston M, Buckley NA, Checketts H, Senarathna L, Mohamed F, Sheriff MH, et al. Speed of initial atropinisation in significant organophosphorus pesticide poisoning-a systematic comparison of recommended regimens. J Toxicol Clin Toxicol 2004;42:865-75.

20. Thunga G, Sam KG, Khera K, Pandey S, Sagar SV. Evaluation of incidence, clinical characteristics and management in organophosphorus poisoning patients in a tertiary care hospital. J Toxicol Environ Health Sci 2010;2:73-6.

21. Eyer P. The role of oximes in the management of organophosphorus pesticide poisoning. Toxicol Rev 2003;22:165-90 